\title{
Comportamento da abelha Trigona spinipes (Fabr.) (Hymenoptera: Apidae) no forrageamento de plantas apícolas: estudos preliminares
}

\section{Behavior of the bee Trigona spinipes (Fabrício, 1793) (Hymenoptera: Apidae) for the forecasting of beekeeping plants: preliminary studies}

Joaci Lucena da Silva Filho ${ }^{1}$ Anderson Antonio Ferreira da Silva ${ }^{1}$ Fernanda Ferreira do Nascimento Silva ${ }^{1}$ Amanda da Silva Lima² Adriana Evangelista-Rodrigues ${ }^{3}$

\author{
${ }^{1}$ Graduando em Zootecnia UFPB/CCA, Areia-PB.; joaci.lucena@ hotmail.com \\ andersonzootec@hotmail.com; nandaferreira3007@gmail.com \\ ${ }^{2}$ Graduada em Zootecnia UFPB/CCA, Areia-PB amandanupam@gmail.com; \\ 3Professora do Departamento de zootecnia UFPB/CCA, Areia-PB. adrianarodriguesufpb@gmail.com
}

\section{Introdução}

A Trigona spinipes é uma espécie de abelha sem ferrão do grupo dos Meliponineos, também conhecida como Irapuá, Arapuá, Arapuã; podendo ser encontrada em diversos lugares do Brasil, e da América do Sul. Com suas mandíbulas cortam as folhas, flores e cortiça, que são materiais fundamentais para construção de seus ninhos (NOGUEIRANETO, 1962).

Entre os Meliponíneos a espécie T. spinipes é a que apresenta maior distribuição geográfica. Diferentemente de outras espécies, seus ninhos não dependem de cavidades préexistentes para serem implantados. Os substratos mais utilizados são galhos, troncos de árvores ou cupinzeiros arbóreos abandonados (MANHÃES et. al., 2012).

Para defender as flores onde estão coletando seus recursos, a Trigona spinipes é bastante agressiva, podendo atacar outras espécies de abelhas como: as abelhas melíferas (Apis melífera) e mamangavas (Xyloccopa sp.) (CORTOPASSI-LAURINO, 1986; NOGUEIRA NETO, 1997; SAZIMA, 1989; NIEH et al., 2005).

A T. spinipes tem grande importância na polinização sendo considerada um polinizador potencial para alguns cultivos, apresentando-se como essencial para a polinização de goiaba, melancia, abacate dentre outros (GIANNINI, JAFFÉ, 2015). Já em 1962, Nogueira-Neto ressaltou que essas abelhas nem sempre inserem a probóscide no nectário, mas penetram nos nectários florais prejudicando o desenvolvimento da flor. $\mathrm{O}$ objetivo do trabalho foi registrar o comportamento forrageiro de abelhas em um campo experimental, avaliando o comportamento da abelha Trigona spinipes na presença de outras espécies polinizadoras.

\section{Fundamentação Teórica}

Forrageamento é o ato as abelhas buscarem e coletarem recursos alimentares a partir de fontes que estão distribuídas em torno da sua colmeia (ADEVA, 2012). Durante muito tempo, as sociedades humanas têm mantido uma estreita relação com as abelhas sem ferrão, principalmente por causa de seu interesse no mel, que constitui no produto mais conhecido da abelha mais conhecido. Além do mel e do pólen, as abelhas sem ferrão hoje em dia têm sido reconhecidas por seu papel como prestadoras de serviços aos ecossistemas, polinizando as culturas e a flora nativa (CARVALHO; MARTINS; MOURÃO, 2014). 
Segundo Imperatriz-Fonseca et al. (2012) o papel funcional dos serviços ecossistêmicos prestados por polinizadores é fundamental na manutenção da biodiversidade e da composição florística e a sua conservação é de valor incalculável, pois atua na base da cadeia alimentar dos biomas.

A competição pode ser definida como interação entre indivíduos provocada pela necessidade comum de um recurso e que leva à redução da sobrevivência, crescimento e/ou reprodução de pelo menos alguns dos indivíduos competidores envolvidos. A competição por recursos pode ser tanto por exploração quanto por meio de interferência (DUIJNS \& PIERSMA, 2014).

A competição tende a ocorrer de forma mais intensa intraespecificamente, já que indivíduos da mesma espécie dividem recursos florais semelhantes. Apesar disso, a competição interespecífica também pode ser intensa, pois pode ocorrer sobreposição de nichos entre espécies diferentes (FERREIRA \& ABSY, 2015).

As abelhas operárias de $T$. spinipes podem alterar seu comportamento, frente a modificação das condições meteorológicas, devido a variação diária ou sazonal do fluxo de recursos alimentares existentes (HILÁRIO et al., 2000).

\section{Material e Métodos}

Realizou-se a pesquisa no Jardim experimental do Setor de Apicultura e Meliponicultura do Departamento de Zootecnia do Centro de Ciências Agrárias/UFPB, Campus II, no município de Areia - PB.

A cidade de Areia está situada na Região do Brejo Paraibano com coordenadas geográficas de $06^{\circ} 57^{\prime} 48^{\prime \prime}$ Latitude Sul e $35^{\circ} 41^{\prime} 30^{\prime \prime}$ Longitude Oeste de Greenwich, a uma altitude de 618 metros. Apresenta um clima do tipo AS' quente e úmido com chuvas de outono-inverno segundo classificação de KOPPEN, e um período de estiagem de 5 a 6 meses.

A temperatura média encontra-se em torno de $22^{\circ} \mathrm{C}$, apresentando os meses de janeiro e fevereiro como os mais quentes e julho e agosto como os mais frios. A umidade relativa apresenta-se pouco variável, com médias compreendendo uma faixa de 80 a $90 \%$ durante maior parte do ano.

Observou-se por um período de 10 dias no turno vespertino, parâmetros da abelha $T$. spinipes em 10 plantas (Tabela 1). A amostragem utilizada foi Animal Focal, numa área de $1 \mathrm{~m}^{2}$ para cada planta experimental.

Os parâmetros observados foram divididos em duas etapas: enumerados de 1 a 4, o comportamento na planta, da abelha $T$. spinipes e de outras espécies, assim conceituados: 1 (abelhas presentes nas plantas antes da presença da abelha T. spinipes), 2 (abelhas de $T$. spinipes confrontando abelhas de outras espécies durante o forrageamento), 3 (abelhas de $T$. spinipes forrageando ao mesmo tempo com abelhas de outras espécies) e 4 (abelhas de outras espécies forrageando após a abelha $T$. spinipes). A segunda etapa foi a frequência de abelhas nas diferentes plantas estudadas, avaliando a atratividade das mesmas para o forrageamento das abelhas.

De posse dos dados, os resultados foram tabulados e submetidos à análise estatística pelo programa SAS aplicando o teste Qui-quadrado para a frequência no estudo de comportamento e Tukey a 5\% de probabilidade para o teste de média da atratividade das plantas estudadas. 
Tabela 1 - Plantas utilizadas como unidades experimentais.

\begin{tabular}{lll}
\hline Identificação das plantas & Nome popular & Nome científico \\
\hline Planta 1 & Amor agarradinho & Antigonon leptopus \\
Planta 2 & Jasmim & Jasminum officinale L. \\
Planta 3 & Girassol & Helianthus annuus \\
\hline Planta 4 & Flamboyanzinho & Caesalpinia \\
\hline Planta 5 & Ypulcherrima \\
\hline Planta 6 & Bastão-do-imperador & Tecoma stans \\
\hline Planta 7 & Cosmo & Cosmos bipinnatus \\
\hline Planta 8 & Plumbago azul & Plumbago auriculata \\
\hline Planta 9 & Jasmim-do-caribe & Plumeria pudica \\
Planta 10 & Botão de ouro & Unxia kubitzkii \\
\hline
\end{tabular}

\section{Resultados e Discussão}

Os resultados mostram que em todas as plantas avaliadas foram observadas várias espécies de abelhas, entre elas a Apis mellifera, Melipona scutellaris e Plebeia sp, além da T. spinipes, nos 4 comportamentos estudados. Pelo teste estatístico, não houve diferença significativa entre os comportamentos observados. Analisando os 4 comportamentos, verificou-se que com exceção das plantas 1 e 7, nas outras plantas, em algum momento da pesquisa, elas deixaram de apresentar pelo menos 1 dos 4 comportamentos. As plantas 2,3,5,8 e 9 não apresentaram confronto entre as espécies de abelhas, sendo estas plantas utilizadas por várias espécies de abelha ao mesmo tempo, durante a florada. Apenas as plantas 4,6 e 9 não apresentaram visitas de outras espécies após a visita da $T$. spinipes, indicando que esta abelha provavelmente não faz limitação de área que impeça a atratividade da planta para outras abelhas. Identificou-se que para o comportamento 3, as plantas 3,4,5,8 e 9 não apresentaram índices de visitação, indicando que para esse comportamento deve-se fazer mais estudos.

De todas as plantas estudadas, a que apresentou maior atratividade para a $T$. spinipes foi o Amor agarradinho (Antigonon leptopus), diferindo estatisticamente para o Jasmim-docaribe (Plumeria pudica) que apesar de liberar um agradável aroma, não atraiu esta abelha para a visitação durante o período de florada. Para o estudo com as outras espécies de abelhas presentes na área experimental, houve diferença estatística com o Cosmo (Cosmos bipinnatus) e o Amor agarradinho (Antigonon leptopus) apresentando-se como os mais atrativos. As plantas menos atrativas foram: Bastão-do-imperador, Plumbago azul, Girassol, Flamboyanzinho, Ipê-mirim e Botão de ouro. 
Os resultados apontam que a abelha $T$. spinipes pode ser mantida em ambientes naturalmente cultivados com plantas apícolas sem que haja ameaça a outras espécies como a Apis mellifera, Melipona scutellaris e Plebeia sp. Este resultado pode ser utilizado como instrumento para a conscientização de apicultores na preservação da abelha Trigona spinipes, pois a mesma não causa danos para outras abelhas.

\section{Conclusão}

A abelha Trigona spinipes não apresenta comportamento territorialista que ameace o forrageamento de outras espécies de abelhas.

Diferentes plantas podem ser forrageadas por várias espécies de abelhas ao mesmo tempo.

\section{Referências}

ADEVA, J.J.G. Simulation modelling of néctar and pollen foraging by honeybees.

Biosystems Engineering, v. 112, n. 4, p. 304-318, 2012.

CARVALHO, R. M. A.; MARTINS. C. F.; MOURÃO, J. S. Meliponiculture in

Quilombola communities of Ipiranga and Gurugi, Paraíba state, Brazil: na

ethnoecological approach. Journal of Ethnobiology and Ethnomedicine, v. 10, n. 3, p. 112, 2014.

CORTOPASSI-LAURINO, M. Politrofia da abelha nativa Trigona (T.) spinipes (irapuá). In: CONGRESSO BRASILEIRO DE ZOOLOGIA, 13., Cuiab·, 1986. Anais... Cuiabá. [s.n.], 1986. p. 98.

DUIJNS, S.; PIERSMA, T. Interference competition in a sexually dimorphic shorebird: prey behaviour explains intraspecific competition. Animal Behaviour. 2014. 92: $195-201$.

FERREIRA, M. G.; ABSY, M. L. Pollen niche and trophic interactions between colonies of Melipona (Michmelia) seminigra merrillae and Melipona (Melikerria) interrupta (Apidae: Meliponini) reared in floodplains in the Central Amazon. Arthropod-Plant Interactions. 2015. 9: 263 - 279. 
GIANNINI, T. C. e JAFFÉ, R. O papel das abelhas irapuás como polinizadores na agricultura e em habitats degradados. http://abelha.org.br/opapeldasabelhasirapuas comopolinizadoresnaagriculturaeemhabitatsdegradados/print, acesso em 25 de Maio de 2016.

Hilário, S.D., Imperatriz-Fonseca, V.L., Kleinert, A.M.P. 2000. Flight activity and colony strength in the stingless bee Melipona bicolor (Apidae, Meliponinae). Revista Brasileira de Biologia 60: 299-306.

Imperatriz-Fonseca, V. L., Canhos, D. A. L., Alves, D. A., Saraiva, A. M. 2012. Polinizadores do Brasil: Contribuição e perspectivas para a biodiversidade, uso sustentável, conservação e serviços ambientais. São Paulo: Editora da Universidade de São Paulo, 488 p.

MANHÃES, V. F., MARQUES, M. F., GAGLIANONE, M. C. Aspectos do comportamen- to de Trigona Spinipes (Fabricius, 1793) em área urbana e confecção de material de divulgação sobre as abelhas-sem-ferrão (apidae: meliponina) na região Norte do Estado do RJ. IV Congresso Fluminense de Iniciação Científica e Tecnológica, 2012.

NIEH, J. C.; KRUIZINGA, K.; BARRETO, L. S.; CONTRERA, F.A.L.; IMPERATRIZ FONSECA, V. L. Effect of group size on the aggression strategy of an extirpating stingless bee, Trigona spinipes. Insects and Society, [Ames], v. 52, p. 147-154, 2005. NOGUEIRA-NETO, P. Vida e criação de abelhas indígenas sem ferrão. São Paulo: Nogueirapis, 1997. 446 p.

SAZIMA, I.; SAZIMA, M. Mamangavas e irapuás (Hymenoptera, Apoidae): visitas, interáveis e conseqüências para polinização do maracujá•(Passifloraceae). Revista Brasileira de Entomologia, Curitiba, v. 33, p. 109-118, 1989. 